\title{
Purple Grape Juice, an Important Flavonoids Source, Influence in Biochemical Parameters in Offspring of Wistar Rats
}

\author{
Daniele Karina Hilger ${ }^{1}$, Mariane Farias Wohlenberg', Thays Krischke Schaffer ${ }^{1}$, \\ Fernanda de Souza Machado', Luciana Kneib Gonçalves', Gabrielli Bortolato', \\ Gabriele Dani², Adriana Rodrigues ${ }^{3}$, Cláudia Funchal', Caroline Dani1 ${ }^{*}$ \\ ${ }^{1}$ Centro Universitário Metodista-IPA, Porto Alegre, Brasil \\ ${ }^{2}$ Georgetown University, Washington DC, USA \\ ${ }^{3}$ Faculdade da Serra Gaúcha, Caxias do Sul, Brasil \\ Email: ${ }^{*}$ caroline.dani@metodistadosul.edu.br
}

Received 14 April 2015; accepted 22 May 2015; published 25 May 2015

Copyright (C) 2015 by authors and Scientific Research Publishing Inc.

This work is licensed under the Creative Commons Attribution International License (CC BY).

http://creativecommons.org/licenses/by/4.0/

c) (i) Open Access

\begin{abstract}
Our objective was to evaluate the effect of chronic gestational treatment and post-breast feeding with purple grape juice on the biochemical parameters in offspring of dams. We used 40 male offspring from 14 Wistar rats which received purple grape juice or water by gavage daily for 42 days at a dose of 7 microliters/g. The offspring were divided into groups of water or juice. All received daily purple grape juice or water by gavage for $\mathbf{3 0}$ days after completion of their nursing period at a dose of 7 microliters/g. At the end of the treatment period, the offspring were euthanized by decapitation with its truncal blood collected and subsequently separated the serum from the blood. The measurements were performed by automation or by manual dosing. Considering the gestational factor, grape juice was able to reduce levels of total cholesterol, triglycerides, urea, alanine aminotransferase (ALT), and not alter the levels of creatinine and aspartate aminotransferase (AST) in serum of the offspring. When considering the post-breast feeding factor, grape juice resulted in an improvement in HDL-C. We concluded that purple grape juice was able to produce a beneficial effect on certain biochemical parameters in offspring.
\end{abstract}

\section{Keywords}

Vitis labrusca, Biochemical Profile, Pregnancy, Grape Juice

\footnotetext{
${ }^{*}$ Corresponding author.
}

How to cite this paper: Hilger, D.K., et al. (2015) Purple Grape Juice, an Important Flavonoids Source, Influence in Biochemical Parameters in Offspring of Wistar Rats. Food and Nutrition Sciences, 6, 683-691. 


\section{Introduction}

The main species used in the manufacture of wines and juices in South America is Vitis labrusca, referred to as "rough" or "common" grape [1]. The grape and its derivatives are among the largest sources of phenolic compounds, which are known for antioxidant properties [2]. Among the polyphenols present in grapes, are flavonoids (anthocyanins, catechins and flavonols), the stilbene (resveratrol), phenolic acids (derivatives of cinnamic and benzoic acids) and a wide variety of tannins [3]. Among these stands out resveratrol, a non-flavonoid which is a phenolic compound commonly found in the skin of Bordograpes, Vitis labrusca in particular [4].

The beneficial effects of grape on human health have been extensively proven. Among them are the improvement in the lipoprotein profile, the regulation of platelet aggregation and increased HDL (High Density Lipoprotein), which helps remove LDL (Low Density Lipoprotein) from blood and prevents atherosclerosis [5]-[8]. In addition, a study with red grape juice of Vitis labrusca variety revealed that it was able to reduce the DNA damage caused by carbon tetrachloride (CCl4) in adult rats, and thus could be an ally in the prevention or reduction of damage by oxidative stress [9].

During pregnancy dynamic changes occur in various systems in the body, which can lead to an imbalance in the formation of free radicals and defense capabilities of the antioxidant mechanisms. Thus, the pregnant woman is more exposed to damage by oxidative stress and can thus increase the incidents of diseases that affect the reproductive process [10]-[12].

In this sense, the choice of foods rich in polyphenols during pregnancy could present beneficial effects as an important factor in the health of the fetus and the mother. This was because Arola-Arnal et al. [13] showed that flavonoids and grape seed metabolites were widely distributed in plasma and maternal tissues. However, the data indicated that the transport across the placenta was not efficient for these compounds [13]. In addition, there is not a consensus as to whether the ingestion of substances rich in polyphenols during pregnancy is beneficial. Zielinski et al. [14] have shown that the consumption of these products with antioxidant and anti-inflammatory activity can interfere with the dynamics of the fetal ductus arteriosus and even ductal channelconstriction.

Due to these controversial opinions on the intake of foods rich in polyphenols in pregnancy and its influence on offspring, this study aimed to evaluate the effect of gestational chronic treatment and post-lactation with red grape juice in offspring of female Wistar rats through lipid, hepatic and renal biomarkers.

\section{Materials and Methods}

\subsection{Animals}

Forty male Wistar rats hatchlings from 14 Wistar rats, 21 days old and weighing approximately 50 g, from the bioterium of the Centro Universitário Metodista IPA were used. The animals had free access to commercial food and water and were maintained in light-dark cycle of \pm 12 hours at a temperature of $22^{\circ} \mathrm{C} \pm 1{ }^{\circ} \mathrm{C}$. The whole experiment was developed with the approval of the Ethics Committee on Animal Use (ECAU) of the Centro Universitário Metodista-IPA, number 007/2014.

\subsection{Grape Juice}

The conventional red grape juice of the variety Bordo was ceded by the company Perini Winery. The juices were from the harvest of 2013, all from the same batch.

The grape juice used had the chemical composition shown in Table 1 . The chemical composition was determined using the methods described by Zoecklein et al. [15]. The contents of total and isolated phenols from the grape juice can be seen in Table 2. Total phenol content was measured using Singleton and Rossi's modification of Folin-Ciocalteau's colorimetric method [16]. High performance liquid chromatography (HPLC) analysis was used to quantify the presence of individual phenolic compounds. Before high-performance liquid chromatography analysis, $5 \mathrm{~mL}$ of each sample was filtered through a cellulose membrane with a 0.20 -mm-diameter pore size. The equipment used in the analysis consisted of an LC-DAD Series 1100 (Agilent Technologies, Palo Alto, CA, USA) liquid chromatographic system with a diode array detector system.

\subsection{Treatment}

The doses of purple grape juice were determined by calculating the daily average amount of juice consumed by a 70-kg human male. As a reference, we used a study with humans who received $480 \mathrm{~mL}=$ day [17]. The 
Table 1. Chemical composition of purple grape juice Vitis labrusca.

\begin{tabular}{ccc}
\hline Analysis & Mean & Standard deviation \\
\hline Volatile acidity $(\mathrm{g} \%$ tartaric acid) & 0.70 & 0.00 \\
Volatile acidity in acetic acid $(\mathrm{g} / \mathrm{100 \textrm {g } )}$ & 0.02 & 0.00 \\
Total sugar $(\mathrm{g} / 100 \mathrm{~mL})$ & 17.4 & 0.00 \\
Relative density $\left(\mathrm{at} 20^{\circ} \mathrm{C}\right)$ & 1.07 & 0.0001 \\
Alcoholic degree $(\% \mathrm{v} / \mathrm{v})$ & 0.3 & 0.00 \\
$\mathrm{pH}$ & 3.49 & 0.00 \\
Benzoic acid $(\mathrm{mg} / \mathrm{L})$ & 0.00 & 0.00 \\
Sorbic acid $(\mathrm{mg} / \mathrm{L})$ & 0.00 & 0.00
\end{tabular}

Table 2. Total and isolated phenolic content in purple grape juice Vitis labrusca.

\begin{tabular}{ccc}
\hline Phenolic compound $(\mathrm{mg} / \mathrm{L})$ & Mean & Standard deviation \\
\hline Total phenolic compound & 5698.67 & 58.12 \\
Resveratrol & 0.46 & 0.00 \\
Catechin & 3.76 & 0.16 \\
Epicatechin & 0.85 & 0.01 \\
Hesperidin & 2.03 & 0.03 \\
Rutin & 26.44 & 0.49 \\
Gallic acid & 0.43 & 0.09 \\
Chlorogenic acid & 24.76 & 0.32 \\
\hline
\end{tabular}

amount of juice was administered to the rats according to their body weight.

During pregnancy (approximately 21 days) and breastfeeding of offspring (approximately 21 days), the pregnant rats received by gavage, grape juice or water $(7 \mu \mathrm{L} / \mathrm{g}$ weight), and all received standard ration. After weaning, male offspring were divided into four groups: Group W-W-Composed of seven newborn pups of mothers treated with water during pregnancy, which received water in the post-lactation; Group W-GJ-Composed of eight newborn pups of mothers treated with water during pregnancy who were treated with red grape juice in the post-lactation; Group GJ-W-Composed of 12 newborn pups of mothers treated red grape juice during pregnancy, which received water in the post-lactation; Group GJ-GJ-Composed of 13 newborn pups of mothers treated with red grape juice during pregnancy, and continued to receive grape juice in the post-lactation.

The offspring received red grape juice (Vitis labrusca) or water for 30 days after weaning them. The administration of grape juice or water was given orally (gavage) in a daily regimen, in a concentration of $7 \mu \mathrm{L} / \mathrm{g}$ in weight. After the end of 30 days of treatment and 4 hours fasting, the animals were sacrificed by guillotine decapitation. Truncal blood was collected and the serum was separated and stored at about $0^{\circ} \mathrm{C}$ to carry out the subsequent analyzes.

\subsection{Biochemical Parameters}

Total cholesterol (TC), triglycerides (TG), HDL were used as biochemical markers to assess lipid profile. Liver function was analyzed using alanine aminotransferase (ALT) and aspartate aminotransferase (AST). Urea and creatinine were used as kidney function markers.

Total cholesterol, triglycerides, ALT, AST, urea and creatininetests were obtained through automation (Bioclin-BS120). However HDL measurements were performed manually using a commercial kit (Labtest Diagnostica SA, Minas Gerais, Brazil). The values of LDL and VLDL fractions were not calculated due to the use of different techniques. 


\subsection{Statistical Analysis}

The results were presented as mean and standard error of mean (SEM). Data normality was assessed using the Kolmogorov-Smirnov test. The differences between the groups were analyzed by analysis of variance (two-way ANOVA) followed by Tukey's post-test. $\mathrm{P} \leq 0.05$ was considered significant. All analyzes were performed using Sigma Stat.

\section{Results}

This study aimed to showed the influence of grape juice consumption in pregnancy or after this period, trying to see as this consumption is important to the pups and after to the adults rats. Our results demonstrate that grape juice when administered during pregnancy promotes a reduction in the TC and TG levels, compared to pups derived from mothers treated with water (Figure 1(a), Figure 1(b), respectively), it is possible to see that the groups GJ-W and GJ-GJ had the lowest levels in both parameters $(P<0.05)$. Grape juice consumption in the post-lactation does not generate statistically significant changes. When assessing the difference between the consumption of grape juice or water during pregnancy or post-lactation, two-way ANOVA shows a significant difference only in the coming offspring of gestational maternal consumption ( $\mathrm{P}<0.001$, for TC and TG). To TC levels the grape juice consumption in the pregnancy showed the lowest level $(50.99 \pm 1.14 \mathrm{mg} / \mathrm{dL})$ than the water consumption $(62.86 \pm 1.63 \mathrm{mg} / \mathrm{dL})(\mathrm{P}<0.01)$. Also to TG levels, the grape juice showed the lowest level

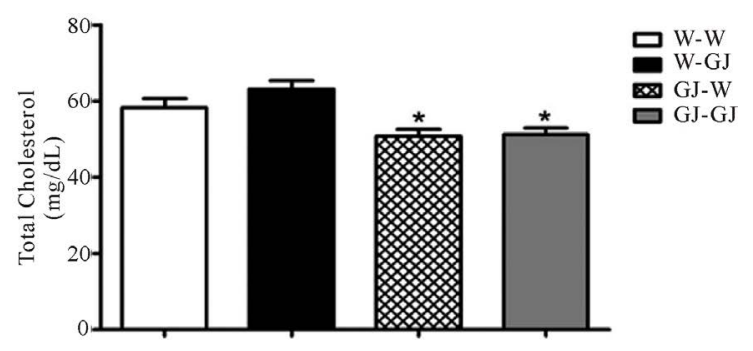

(a)

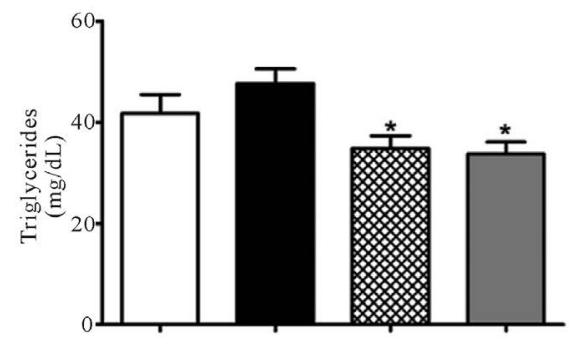

(b)

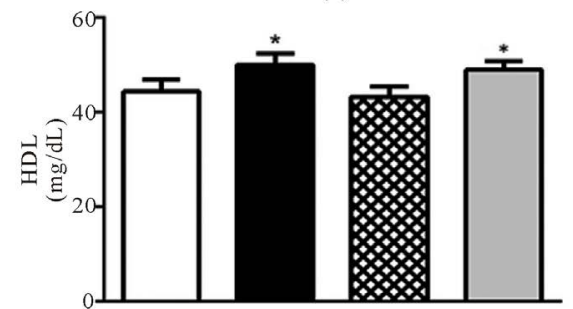

(c)

Figure 1. (a) Total cholesterol concentration (mg/dL); (b) Concentration of triglycerides (mg/dL); and (c) HDL-cholesterol concentration (mg/dL) in the serum of male offspring. W-W: mother consumed water and the pup consumed water; W-GJ: mother consumed water and the pup consumed grape juice; GJ-W: mother consumed grape juice and pup consumed water; GJ-GJ: mother consumed grape juice and pup consumed grape juice. Results are expressed as mean \pm EPM. ${ }^{*} \mathrm{P} \leq 0.05$ bytwo-way ANOVA with Tukey post-test when considering the factor pregnancy or post-lactation. 
$(34.28 \pm 1.93 \mathrm{mg} / \mathrm{dL})$ than the water consumption $(47.06 \pm 2.50 \mathrm{mg} / \mathrm{dL})(\mathrm{P}<0.01)$ However, the effect of consumption post-lactating does not promote difference between the juice or water consumption $(P=0.803,0.993$, TC and TG, respectively).

In contrast, HDL levels (Figure 1(c)) showed an increase in the group treated with grape juice in the postlactating, indicating that the grape juice administered to the pups after weaning was able to significantly increase this parameter. When analyzing the gestational or post-lactation consumption factors, the juice consumption $(49.50 \pm 1.50 \mathrm{mg} / \mathrm{dL})$ was statistically significant if comparing to water group $(43.79 \pm 1.67 \mathrm{mg} / \mathrm{dL})$ only in the post-lactation ( $\mathrm{P}=0.05)$, and the maternal consumption of juice during pregnancy did not influence the levels of HDL of the offspring $(\mathrm{P}=0.612)$.

The results of renal profile markers are shown in Figure 2. Is possible to observe in Figure 2(a) that grape juice consumption in the pregnancy promoveareduction $(24.53 \pm 0.68 \mathrm{mg} / \mathrm{dL})$ in the levels of urea than the water consumption $(29.40 \pm 0.98 \mathrm{mg} / \mathrm{dL})(\mathrm{P}<0.05)$. Grape juice or water consumption in the post-lactation does not influence urea levels $(\mathrm{P}>0.05)$, in other words, the consumption during the pregnancy is very important to provoke a beneficial effect to the pups. Regarding creatinine levels, is shown (Figure 2(b)) that there was no statistical difference between the groups.

Figure 3 shows the results obtained regarding the profile of liver parameters. We found that there was no difference between the levels of AST (Figure 3(a)). However, we can see that the consumption of grape juice in the pregnant rat was responsible for a decline in ALT values in their offspring (Figure 3(b)). To ALT levels the grape juice consumption in the pregnancy showed the lowest level $(35.92 \pm 1.316 \mathrm{mg} / \mathrm{dL})$ than the water consumption $(44.77 \pm 1.0 \mathrm{mg} / \mathrm{dL})(\mathrm{P}<0.01)$. According to two-way ANOVA, the consumption of grape juice during pregnancy influences ALT levels in the offspring $(\mathrm{P}<0.01)$ not seen on the post-lactation consumption $(\mathrm{P}=0.765)$.

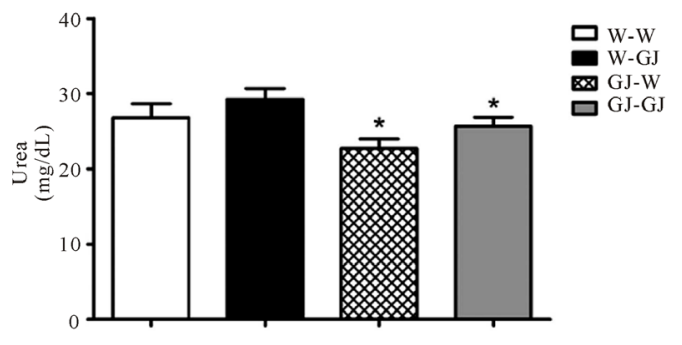

(a)

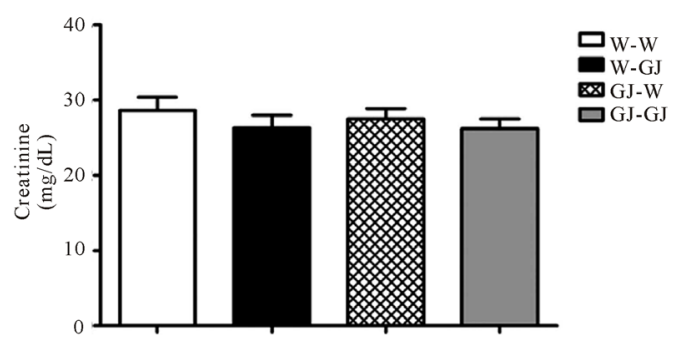

(b)

Figure 2. (a) Concentration of urea (mg/dL) and (b) creatinine concentration (mg/dl) in serum of male offspring. W-W: mother consumed water and the pup consumed water; W-GJ: mother consumed water and the pup consumed grape juice; GJ-W: mother consumed grape juice and pup consumed water; GJ-GJ: mother consumed grape juice and pup consumed grape juice. The results are expressed as mean \pm EPM. ${ }^{*} \mathrm{P} \leq 0.05$ per two-way ANOVA with Tukey post-test when considering the factor pregnancy or post-lactation.

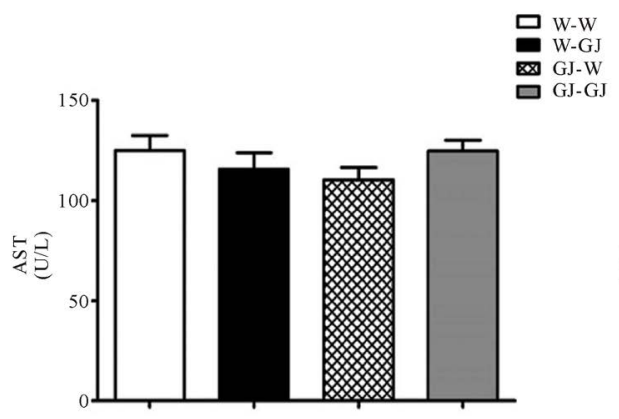

(a)

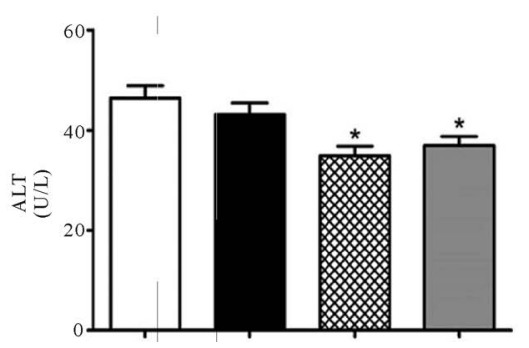

(b)

Figure 3. (a) Concentration AST (U/L) and (b) concentration of ALT (U/L) in serum of male offspring.W-W: mother consumed water and the pup consumed water; W-GJ: mother consumed water and the pup consumed grape juice; GJ-W: mother consumed grape juice and pup consumed water; GJ-GJ: mother consumed grape juice and pup consumed grape juice. The results are expressed as mean \pm EPM. ${ }^{*} \mathrm{P} \leq 0.05$ per two-way ANOVA with Tukey post-test when considering the factor pregnancy or post-lactation. 


\section{Discussion}

In the literature there are many studies showing the association between diets rich in fruits and natural products with the reduction or prevention of damage caused by oxidative stress and anticancer activities and anti-teratogenic [1] [18] [19]. This protective effect has been attributed primarily to the natural compounds present in these foods, such as polyphenols, carotenoids and vitamin C [20]. Among these foods, there is the grape and its derivatives, which are among the largest sources of phenolic compounds [2] [21]. Along with this there is increasing evidence that the maternal diet composition is important in fetal growth and development, including specific aspects of reproduction and pregnancy outcomes, both in animals and humans [22] [23]. Consumption of foods rich in polyphenols contributing to human health is well established in the literature, however there is still no consensus among the researchers about the transgenerational effect.

In the present study, we used the experimental model of pregnant rats to evaluate the effect of chronic treatment with red grape juice on the biochemical parameters of their offspring. The importance of testing blood components is due to the fact that they enable the detection of stress conditions, which may be nutritional, environmental or physical [24]. However, there is still no studies in the literature using this experimental model with grape juice in order to investigate its influence on biomarkers of offspring. Thus, with our results we can see that the grape juice during pregnancy was able to reduce the levels of TC, TG, urea and ALT, and does not interfere with creatinine levels and AST in the serum of pups.

Our analysis demonstrated significant beneficial changes in TG and TC parameters. These results corroborate what was proposed by Hort et al. [25], who in his work used a fraction of non-alcoholic ethyl acetate (EAF) of a Brazilian red wine, obtained from Vitis labrusca grapes. In this study, the researchers demonstrated that their animals showed a significant reduction in the levels of TC, TG, VLDL and LDL when receiving the wine extract, even consuming a hypercholesterolemicdiet. Further, Vinson et al. [26] showed that hyperlipidemic hamsters receiving alcohol-free red wine obtained a reduction in total and LDL cholesterol as compared to controls. Thehyperlipidemic effect of polyphenols in red wine have been associated with the fact that these compounds can bind to cholesterol, blocking its absorption. In this situation, the fecal excretion of cholesterol, bile acids, and other dietary lipids are increased [27]. However, in the study by Zibaeenezhad and colleagues [8], with humans, it was observed that regular consumption of green grape juice (verjuice) typical of the Iran region, for 60 days did not result in reduction of TG, TC or LDL, but indicated an increase in HDL. The difference between the results presented in the literature about the influence of grape juice consumption on TC, TG and HDL can be attributed to the content of polyphenols, as the literature shows that red juices are richer in polyphenols than white juices [1].

The improvement in HDL levels in the offspring who consumed red grape juice in our study is in agreement with several results already published in the literature [6] [7] [28]. In 2006, Castilla and colleagues demonstrated that the consumption of Bordogrape juice in patients undergoing hemodialysis improved HDL levels, and reduce plasma concentrations of LDL [6]. Corroborating Khadem-Ansari et al. [28], where red grape juice consumption $(150 \mathrm{~mL})$ for 30 days significantly increased the serum levels of HDL. These findings may have important implications for the prevention of atherosclerosis in healthy subjects [28].

In the renal profile, our results showed a decrease of urea in the offspring of mothers who received grape juice during pregnancy. The reduction in urea levels through consumption of products rich in polyphenols has been presented by Pinheiro et al. [29], where the grape seed extract (Cabernet sauvignon) promoted a reduction of urea levels in rats that were induced lesion due methotrexate (MTX). In our study no significant change in creatinine levels were observed. These data corroborate Safa et al. [30], where grape seed extract, in a model of acute kidney lesion by gentamicin, showed a protective effect, however without significant changes in the levels of creatinine and urea.

Still, de Bem and colleagues [23] in a transgenerational protection assessment model evaluated the beneficial effect of açaíseed extract (Euterpeoleracea mart.) in cardiovascular and renal changes in rats whose mothers were fed a low protein diet during pregnancy. Among the results, it is observed that the açaí extract normalized the levels of creatinine and urea, elevated because of the low protein diet in the offspring. The benefits of açaí demonstrated in this work confirm data obtained for urea parameter in our study, when considering the gestational factor. In addition, provide further evidence of the antioxidant action of these natural compounds and their ability to cross the placental barrier generating beneficial effects on offspring.

This study showed that there was no statistical difference between the groups regarding AST levels. However, it was observed that the grape juice consumption during pregnancy was responsible for a decline in ALT values. 
Products derived from grape have been shown to promote hepatoprotection, including alcoholic extract of grape seed (Vitis vinifera) in albino rats, reducing levels in AST and ALT [31]. Also, Orhan and colleagues demonstrated that the extract of Vitis vinifera leaves is able to reduce liver damage caused by carbon tetrachloride [32]. Furthermore, Alimi et al. [33] show that the consumption of fruit juice from Cactus opuntiaficusindica f. inermis, which contains antioxidant compounds such as flavonoids polyphenols, betaxanthin and betacyanin reduced levels of AST, ALT and GGT in Wistar rats, suggesting protective role in liver injury induced by ethanol.

\section{Conclusion}

We can conclude that the consumption of red grape juice during pregnancy can lead to benefits for biochemical markers. Briefly, we found that gestational consumption of grape juice promoted on their offspring reduction in TC, TG, urea and ALT parameters, and did not alter the levels of creatinine and AST. Also, the consumption of post-lactating grape juice promoted a significant increase in HDL. This study evaluated one kind of rats models; other studies with others models could be designed to reinforce these results, and also with different interventions during the pregnancy and also in childhood and adult life. Although more studies are required to analyze other biochemical and physiological parameters, and better understand how these mechanisms take place, it is possible to suggest that grape juice promotes a benefit even when consumed during pregnancy to their offspring, thus being an ally in preventing various diseases.

\section{Acknowledgements}

Thanksto Fundação de Amparo à Pesquisa do Estado do Rio Grande do Sul (FAPERGS), Conselho Nacional de Desenvolvimento Científico e Tecnológico (CNPq) and Coordenação de Aperfeiçoamento de Pessoal de Nível Superior (CAPES) for financial support. Instituto Brasileirodo Vinho (IBRAVIN) to the financial and promotional support and Winery Perini for the cession of juice.

\section{Declaration of Interests}

The authors declare no conflict of interest.

\section{References}

[1] Dani, C., Oliboni, L.S., Bonatto, D., Vanderlinde, R., Salvador, M. and Henriques, J.A. (2007) Phenolic Content and Antioxidant Activities of White and Purple Juices Manufactured with Organically-Produced Grapes. Food and Chemical Toxicology, 45, 2574-2580. http://dx.doi.org/10.1016/j.fct.2007.06.022

[2] Miyagi, Y., Miwa, K. and Inoue, H. (1997) Inhibition of Human Low Density Lipoprotein Oxidation by Flavonoids in Red Wine and Grape Juice. American Journal of Cardiology, 80, 1627-1631. http://dx.doi.org/10.1016/S0002-9149(97)00755-8

[3] Mazza, G. (1995) Anthocyanins in Grapes and Grape Products. Critical Reviews in Food Science and Nutrition, 35, 341-371. http://dx.doi.org/10.1080/10408399509527704

[4] Oak, M.H., ElBedoui, J. and Schini-Kerth, V.B. (2005) Antiangiogenic Properties of Natural Polyphenols from Red Wine and Green Tea. The Journal of Nutritional Biochemistry, 16, 1-8. http://dx.doi.org/10.1016/j.jnutbio.2004.09.004

[5] Belguendouz, F.L. and Gozzelino, M.T. (1998) Interaction of Transresveratrol with Plasma Lipoproteins. Biochemical Pharmacology, 15, 811-816. http://dx.doi.org/10.1016/S0006-2952(97)00544-3

[6] Castilla, P., Echarri, R., Da’valos, A., Cerrato, F., Ortega, H., Teruel, J., Lucas, M., Gómez-Coronado, D., Ortuño, J. and Lasunción, M. (2006) Concentrated Red Grape Juice Exerts Antioxidant, Hypolipidemic, and Antiinflammatory Effects in Both Hemodialysis Patients and Healthy Subjects. The American Journal of Clinical Nutrition, 84, 252-262.

[7] Stein, J.H., Keevil, J.G., Wiebe, D.A., Aeschlimann, S. and Folts, J.D. (1999) Purple Grape Juice Improves Endothelial Function and Reduces the Susceptibility of LDL Cholesterol to Oxidation in Patients with Coronary Artery Disease. Circulation, 100, 1050-1055. http://dx.doi.org/10.1161/01.CIR.100.10.1050

[8] Zibaeenezhad, M., Mohammadi, E., Beigi, M.A., Mirzamohammadi, F. and Salehi, O. (2012) The Effects of Unripe Grape Juice on Lipid Profile Improvement. Cholesterol, 2012, Article ID: 890262. http://dx.doi.org/10.1155/2012/890262

[9] Dani, C., Oliboni, L.S., Umezu, F.M., Pasquali, M., Salvador, M., Moreira, J.C. and Henriques, J.A. (2009) Antioxidant and Antigenotoxic Activities of Purple Grape Juice-Organic and Conventional—In Adult Rats. Journal of Medicinal Food, 12, 1111-1118. http://dx.doi.org/10.1089/jmf.2008.0256 
[10] Agarwal, A. and Allamaneni, S.S. (2004) Role of Free Radicals in Female Reproductive Diseases and Assisted Reproduction. Reproductive BioMedicine Online, 9, 338-347. http://dx.doi.org/10.1016/S1472-6483(10)62151-7

[11] Agarwal, A., Gupta, S. and Sikka, S. (2006) The Role of Free Radicals and Antioxidants in Reproduction. Current Opinion in Obstetrics and Gynecology, 18, 325-332. http://dx.doi.org/10.1097/01.gco.0000193003.58158.4e

[12] Vannuchi, C.I., Jordao, A.A. and Vannuchi, H. (2007) Antioxidant Compounds and Oxidative Stress in Female Dogs during Pregnancy. Research in Veterinary Science, 83, 188-193. http://dx.doi.org/10.1016/j.rvsc.2006.12.009

[13] Arola-arnal, A., Oms-Oliu, G., Crescenti, A., Del Bas, J.M., Ras, M.R., Arola, L. and Caimari, A. (2013) Distribution of Grape Seed Flavanols and Their Metabolites in Pregnant Rats and Their Fetuses. Molecular Nutrition \& Food Research, 57, 1741-1752. http://dx.doi.org/10.1002/mnfr.201300032

[14] Zielinsky, P., Piccoli, A.L., Manica, J.L.L. and Nicoloso, L.H. (2010) New Insights on Fetal Ductal Constriction: Role of Maternal Ingestion of Polyphenol-Rich Foods. Expert Review of Cardiovascular Therapy, 8, 291-298. http://dx.doi.org/10.1586/erc.09.174

[15] Zoecklein, B.W., Fugelsang, K.C., Gump, B.H. and Nury, F.S. (2000) Wine Analysis and Production. Aspen Publishers, Maryland.

[16] Singleton, V.L., Orthofer, R. and Lamuela-Ravento’s, R.M. (1999) Analysis of Total Phenols and Other Oxidation Substrates and Antioxidants by Means of Folin-Ciocalteau Reagent. Methods in Enzymology, 299, 152-178.

[17] Park, Y.K., Park, E., Kim, J. and Kang, M. (2003) Daily Grape Juice Consumption Reduces Oxidative DNA Damage and Plasma Free Radical Levels in Healthy Koreans. Mutation Research, 529, 77-86. http://dx.doi.org/10.1016/S0027-5107(03)00109-X

[18] Dani, C., Pasquali, M.A., Oliveira, M.R., Umezu, F.M., Salvador, M., Henriques, J.Á. and Moreira, J.C. (2008) Protective Effects of Purple Grape Juice on Carbon Tetrachloride-Induced Oxidative Stress in Brains of Adult Wistar Rats. Journal of Medicinal Food, 11, 55-61. http://dx.doi.org/10.1089/jmf.2007.505

[19] Dani, C., Oliboni, L.S., Pasquali, M.A., Oliveira, M.R., Umezu, F.M., Salvador, M., Moreira, J.C. and Henriques, J.A. (2008) Intake of Purple Grape Juice as a Hepatoprotective Agent in Wistar Rats. Journal of Medicinal Food, 11, $127-$ 132. http://dx.doi.org/10.1089/jmf.2007.558

[20] Ferguson, L.R. (2001) Role of Plant Polyphenols in Genomic Stability. Mutation Research, 475, 89-111. http://dx.doi.org/10.1016/S0027-5107(01)00073-2

[21] Shahidi, F. and Wanasundara, P.K. (1992) Phenolic Antioxidants. Critical Reviews in Food Science and Nutrition, 32, 67-103. http://dx.doi.org/10.1080/10408399209527581

[22] Al-gubory, K.H., Fowler, P.A. and Garrel, C. (2010) The Roles of Cellular Reactive Oxygen Species, Oxidative Stress and Antioxidants in Pregnancy Outcomes. The International Journal of Biochemistry \& Cell Biology, 10, 1634-1650. http://dx.doi.org/10.1016/j.biocel.2010.06.001

[23] de Bem, G.F., da Costa, C.A., de Oliveira, P.R., Cordeiro, V.S., Santos, I.B., de Carvalho, L.C., Souza, M.A., Ognibene, D.T., Daleprane, J.B., Sousa, P.J., Resende, A.C. and de Moura, R.S. (2014) Protective Effect of Euterpeoleracea Mart (Açaí) Extract on Programmed Changes in the Adult Rat Offspring Caused by Maternal Protein Restriction during Pregnancy. Journal of Pharmacology and Pharmacotherapeutics, 66, 1328-1338. http://dx.doi.org/10.1111/jphp.12258

[24] Aderimi, F.A. (2004) Effects of Replacement of Wheat Bran with Cassava Root Sieviate Supplemented or Unsupplemented with Enzyme on Hematology and Serum Biochemistry of Pulled Chicks. Journal of Tropical Forest Science, 7, 147-153.

[25] Hort, M.A., Schuldt, E.Z., Bet, A.C., DalBó, S., Siqueira, J.M., Ianssen, C., Abatepaulo, F., de Souza, H.P., Veleirinho, B., Maraschin, M. and Ribeiro-do-Valle, R.M. (2012) Anti-Atherogenic Effects of a Phenol-Rich Fraction from Brazilian Red Wine (Vitis labrusca L.) in Hypercholesterolemic Low-Density Lipoprotein Receptor Knockout Mice. Journal of Medicinal Food, 15, 936-44. http://dx.doi.org/10.1089/jmf.2011.0333

[26] Vinson, J.A., Teufel, K. and Wu, N. (2001) Red Wine, Dealcoholized Red Wine, and Especially Grape Juice, Inhibit Atherosclerosis in a Hamster Model. Atherosclerosis, 156, 67-72. http://dx.doi.org/10.1016/S0021-9150(00)00625-0

[27] Perez-Jimenez, J. and Saura-Calixto, F. (2008) Grape Products and Cardiovascular Disease Risk Factors. Nutrition Research Reviews, 21, 158-173. http://dx.doi.org/10.1017/S0954422408125124

[28] Khadem-Ansari, M., Rasmi,Y. and Ramezani, F. (2010) Effects of Red Grape Juice Consumption on High Density Lipoprotein-Cholesterol, Apolipoprotein AI, Apolipoprotein B and Homocysteine in Healthy Human Volunteers. The Open Biochemistry Journal, 4, 96-99. http://dx.doi.org/10.2174/1874091X01004010096

[29] Pinheiro, F.V., Pimentel, V.C., De Bona, K.S., Scola, G., Salvador, M., Funchal, C. and Moretto, M.B. (2010) Decrease of Adenosine Deaminase Activity and Increase of the Lipid Peroxidation after Acute Methotrexate Treatment in Young Rats: Protective Effects of Grape Seed Extract. Cell Biochemistry and Function, 28, 89-94. http://dx.doi.org/10.1002/cbf.1627 
[30] Safa, J., Argani, H., Bastani, B., Nezami, N., RahimiArdebili, B., Ghorbanihaghjo, A., Kalagheichi, H., Amirfirouzi, A., Mesgari, M. and Soleimany Rad, J. (2010) Protective Effect of Grape Seed Extract on Gentamicin-Induced Acute Kidney Injury. Iranian Journal of Kidney Diseases, 4, 285-291.

[31] Ahmad, F. and Khan, G.M. (2012) Study of Aging and Hepatoprotective Activity of Vitis vinifera L. Seeds in Albino Rats. Asian Pacific Journal of Tropical Biomedicine, 2, S1770-S1774. http://dx.doi.org/10.1016/S2221-1691(12)60492-4

[32] Orhan, D.D., Orhan, N., Ergun, E. and Ergun, F. (2007) Hepatoprotective Effect of Vitis vinifera L. Leaves on Carbon Tetrachloride-Induced Acute Liver Damage in Rats. Journal of Ethnopharmacology, 112, 145-151. http://dx.doi.org/10.1016/j.jep.2007.02.013

[33] Alimi, H., Hfaeidh, N., Mbarki, S., Bouoni, Z., Sakly, M. and Rouma, K.B. (2012) Evaluation of Opuntia ficus indica F. Inermis Fruit Juice Hepatoprotective Effect upon Ethanol Toxicity in Rats. General Physiology and Biophysics, 31, 335-342. http://dx.doi.org/10.4149/gpb_2012_038 